\title{
Facile Light-Triggered One-Step Synthesis of Small and Stable Platinum Nanoparticles in Aqueous Medium From a $\beta$-Cyclodextrin Host-Guest Inclusion Complex.
}

Salvatore Giuffrida, Giorgio Ventimiglia, Salvatore Petralia, Sabrina Conoci and Salvatore Sortino*

\section{Supporting Information}

All reagents were obtained from Sigma-Aldrich and used as received. All glassware used was immersed in piraña at $70^{\circ} \mathrm{C}$ for $1 \mathrm{~h}$. Warning: piraña solution should be handled with caution. Next, the glassware was rinsed with large amounts of high-purity water and dried. Water was purified through a Millipore Milli-Q system. The solutions of the hostguest complex were prepared by adding $10 \mathrm{mg}$ of Pt-acac to a $10^{-2} \mathrm{M}$ aqueous solution of $\beta$-CD. The mixture was stirred for $1 \mathrm{~h}$ at room temperature and than filtered through a 0.2 $\mu \mathrm{m}$ cellulose acetate filter, Millipore.

Irradiation was performed in a $10 \mathrm{~mm}$ quartz cuvett with $3 \mathrm{~mL}$ capacity using a Rayonet photochemical reactor equipped with 4 RPR lamps with an emission in the 380$480 \mathrm{~nm}$ range with a maximum at $420 \mathrm{~nm}$. The solution was gently stirred during the

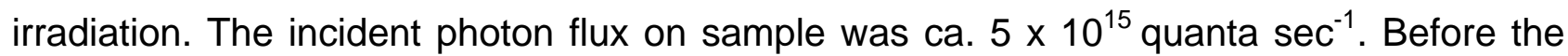
period of aging, the solution of Pt nanoparticles was diluted 10-fold.

Absorption and induced circular dichroism spectra were recorded with a Jasco V560 spectrophotometer and a Jasco J-715 dichrograph, respectively. TEM images were obtained by means of a FEG JEM 2010F instrument with a field emission gun operating at $200 \mathrm{kV}$. The electro-optical configuration guarantees ultra high spatial resolution (0.19 $\mathrm{nm}$ ). This microscope is equipped with the GIF (Gatan Image Filter) apparatus which allows realizing images filtered to narrow windows of the electron energy loss spectrum. 